\title{
TOWARDS A CORE VOCABULARY FOR A NATURAL LANGUAGE SYSTEM
}

\author{
llubert I chmann \\ IBM Deutschland GmbII, Scientific Center \\ Institute for Knowledge Based Systems \\ Wilckensstr. la \\ I)-6900 IIcidelberg, (jermany \\ Iimail: IIIII at DIIIIIBMI.IBIINI:I'
}

\begin{abstract}
The desire to construct robust and portable natural language systems has led to research on how a corc vocabulary for such systems can be defined. Statistical methods and scmantic criteria for doing this are discussed and compared. Currently it does not seem possible to preciscly definc the notion of core vocabulary, but it is argued that workable criteria can nevertheless be found. linally it is emphasized that the implementation of a core vocabulary must be seen as a long-range rescarch program rather than as a short-term goal.
\end{abstract}

\section{Motivation}

Reascarch on matural language processing systems today strives for the construction of robust and portable systems.' $\wedge$ system is robust, if it can handle a large varicty of user inputs without giving up or producing unexpected results. $\Lambda$ system is portable in the sense intended here, if it is not geared to a single subject domain, but can be ported with a reasonable effort to a variely of subject domains. It is common understanding that there exists a central fragment of a language which 1 . is recpuired for dealing with virtually any subject domain, and 2 . is invariant with respect to meaning and use accross subject domains. It is of course a non-trivial empirical question whether such a central fragenent really exists, and if so, to say what it is, but a number of researchers secm to share the assumption that it does (cf. c.g. Alshawi et al. (1988)). Any robust and portable system would then have to handle this core fragment.

In this paper I am concerned with a second - related - assumption, namely that there exists a core vocabulary which is needed for handling any subject domain. This assumption is also shared by many rescarchers, and it underlies the production of basic vocabularies for language learning such as (Ochler (1980). Usually the authors claim that their word lists are based on statistical investigations, but they also cmphasizc that they did not slavishly stick to the statistics but used additional critcria such as "usage valuc", "availability", "familiarity", or "learnability" without ever saying how these are established."

I will address the following questions:

1. Ilow can the intuitive notion of core vocabulary he properly defined?

2. How can statistical metheds be employed to define a core vocabulary and how do they relate to semantic criteria?

3. What semantic critcria can be found to define a core vocabulary?

\section{Definitions of a core vocabulary}

lhere are several ways to define core vocabulary, I can think of the following three:

1. The core vocabulary consists of the $n$ most frequent words of a language.

2. The core vocabulary is that vocabulary which is common to all native speakers of a latnguage.

3. The semantic core vocibulary consists of those words which sullice to define all of the remaining vocabulary of a language.

The first two definitions call for statistical incthods which shall be discussed in the next section, and the third one obviously requires a semantic approach which shall be discussed in section "Scmantic criteria".

\section{Statistical methods}

Jirequency counts have well established the basic properties of the frequency distribution for text corpora. Thus in Kucera and lirancis (1967) we get coverage ligures like this for their complete corpus of about 1 million tokens:

$\begin{aligned} 10 \text { most frequent words: } & 24.26 \% \\ 100 \text { most frequent words: } & 47.43 \% \\ 1000 \text { most frequent words: } & 68.86 \%\end{aligned}$

1 The research described liere has been conducted in the context of the $1.11,0$ ( project (IIerzog et al., 1986). It has profited from intensive discussions with $R$. Mayer. Much of the underlying statistical work on text corpora is duc to $\mathrm{U}$. Bandara and $\mathrm{i}$. Walch from the speceth recognition project SPRING (Wothke et al., 1989).

2 Our investigations are based on (jerman, but for ease of reference also some Iinglish examples are given. 
These figures vary only slightly with corpus size, and also for (jerman similar values are observed. Ilowever, while coverage figures are rather stable with respect to the $n$ most frequent words of a corpus, what are the $n$ most frequent words may vary widely with corpora or subcorpora. Two parametcrs responsible for this variation are obvious:

1. Subject matter and

2. Communicative function.

Thus in the "Kultur" section of a newspaper which we have analyzed we see that words like Musik, Thealer, Regisseur, etc. occur with a drastically higher frequency than in the other scctions, which of course can be attributed to subject inatter. But personal pronouns, in particular Ist and 2 nd person pronouns, also show a much higher frequency, and this can hardly be attributed to subject matter, rather to different communicative functions of feuilletonistic writing and say economic news.

All of this relates of course to the much discussed issuc of what constitutes a representatitve corpus for statistical linguistic analysis. Since specific subject matters and communicative functions vary in importance for different speakcrs of a language, it will be difficult if not impossible to eliminate arbitrariness. Rather, a definition of representative corpus must take into account the research goals pursued.

fior a natural language system which is supposed to analyze and gencrate texts, to cngage in dialogues wilh users, and which is to acquire knowledge from the analysis of definitions and rules formulated in nalural language, one needs a corpus of texts where all these aspects are sufficiently represented. IVe were able to draw upon a varicty of corpora none of which would show all the features required, but the combination of them secms to be quite reasonable.

We compared the following five word lists:

1. Ochler (1980): (irundwortschatz consisting of 2247 words,

2. Irk (1972): scientific texts from 34 disciplines, 1283 words with frequency $\geq 20$,

3. Pregel/Rickhcit (1987): texis by primary school children, 593 words with frequency $\geq 20$,

4. SPRING-corpus of newspaper texts, 2733 most frequent words,

5. DUJDEN (1989): definitions for words beginning with $a, 2693$ words with frequency $\geq 4$

I'rom these, word lists $B_{n}$ were formed consisting of those words occurring in at least $n$ of the original word lists $(1 \leq n \leq 5)$. The lengths of these lists are $B_{1}: 5409, B_{2}: 2248, B_{3}: 1215, B_{4}: 565$, and $B_{5}: 116$.
The size of $B_{5}$ shows that a really common core of a variety of texts may be extremely sinall, the successive losening of restrictions used here allows for a balanced extension of this very small core. The list $B_{3}$ was chosen as the statistical core rocabulary serving as a hase for applying semantic critcria, because the overall core vocabulary was envisaged to have a size of approx. 1500 words. Inspection shows that many intuitively basic words and very few idiosyncratic words are contained due to the method of intersecting the word lists. Ilence, $B_{3}$ seems quite reasonable.

\section{Semantic criteria}

If one takes the $n$ most frequent words of any frequency count one will no doubt discover that these words will not exhibit a linguistic closure in the sense that natural sentences can be formed with all and only the words in the set. liurther onc will sce that semantic relations will be incomplete. Thus one finds in Ochler (1980) which is hased on the old Kacding count that weiblich (female) occurs but not its antonym männlich (male). Ior a core vocabulary to be set up for a natural language system, I think, one must strive for linguistic elosure, since otherwise, one ends up with words one cannot use. This means that you cannot base the core vocabulary on frequency counts alone.

liurthermore, one cannot expect that one will have just the vocabulary necded to formulate definitions for the words in the list chosen. To avoid circularity, one will have to accept that certain words cannot be defined within the vocabulary, but one will also have to aceept that for some words less than complete definitions can be given. Because of this lack of delinability, a scmantic core vocabulary can only be understood as an approximative notion geared towards "the hest one can do". What one can hope to do, is 10 deline

1. taxonomic relations,

2. "sclectional restrictions" or constraints on scmantic compatibility, and

3. meaning rules of arbitrary complexity (including classical definitions).

1 propose to formulate all of these types of rules in natural language for $B_{3}$ trying $t o$ stay within at least the vocabulary of $B_{1}$, to add the words used in the formulations to the original set, and continue until one cannot think of further rules. I claim that one can achicve a fixed point from where on no new words are added to the set, and that at this moment one has reached a rather good approximation to a semantic core vocabulary.

There is undoubtedly a relationship between frequency and semantic relevance: since taxonomic relations are often exemplified by anaphoric references, since semantic compatibility constraints lead to the co-occurrence of ap- 
propriate words, and since other more complex scmantic relationships are bound to be exhibited in the various threads of discourse, one has all reason to cxpect a certain amount of congruence belween frequency counts and the semantic core vocabulary as defined above.

'The work on formulating taxonomic relations, scmantic constraints and other meaning rules is underway, and since it will involve all of the vocabulary, linguistic closure will be achicved at the same time.

$\Lambda$ s an example, take a taxonomic rule for $A r m$ which is in $B_{3}$

Jeder $\left(B_{3}\right)$ Arm ist Teil $\left(B_{1}\right)$ eines Körpers $\left(B_{3}\right)$. (Every arm is part of a body.)

The word Körperleil (body parl) is only available in $B_{1}$ and was therefore not uscel, or instead of Teil one could also have used Gilied $\left(B_{3}\right.$, nember), but then the rule would not have covered arms of machincs or rivers. This highlights a big problem in the natural language formulation of mcaning rulcs: how is ambiguity dealt with? Space docs not permit a full discussion here, therefore suffice it to say that it is onc of our research goals to formulate meaning rules which specify criteria for disambiguation.

\section{Linguistic description}

The preceding discussion has concentrated on how to cstablish a core vocabulary. Now a few brief remarks shall follow on how the words of the core vocabulary can be linguistically described.

The morphology of languiges such as German is well understood and has been coded for an extended vocabulary in the lexical database of the IJIX project (Barnott et al., 1986). This database also contains detailed syntactic information, in particular on government patterns.

It is the description of the semantic (and pragmatic) properties of many words one would obviously want to include in a core vocabulary that will confront us with huge unsolved theoretical problems. Bc it modal verbs or propositional attitudes, sentence adverbs or "abstract" nouns of various kinds. Investigations on some individual words have generated heaps of literaturc, for others it seems that people have not cven dared to look at them. Does this make the enterprise of implementing a core vocabulary a futile onc? I think not. I think the implementation of a core vocabulary should be $\operatorname{secn}$ as a long-range research goal for both computational and theorctical linguistics, and furthermore that natural language systems provide a good environment for doing cxperiments in semantics, be- (ause they encourage an integrated treatment of linguistic phenomena.

\section{Conclusions}

Our rescarch on establishing a corc vocabulary for German in the framework of the I.II,OG project has revealed that currently no absolute definition can be given, but ways have been shown how to arrive at a working definition with respect to the objectives of natural language systems. It has been shown that both statistical methods and semantic critcria can, and I think, have to contribute to the establishment of a core vocabulary.

The linguistic description and thus the implementation of a corc vocabulary depends heavily on progress in theoretical linguistics, in particular in semantics and pragmatics, but I want to stress that focussing on a core vocabulary is a fruitful way to direct linguistic research, which can be supported by the need for integrated treatments in natural language systems.

\section{References}

Nlshawi, II., D. M. Carter, J. van Iijck, R. C. Moore, D. B. Moran, I. C. N. I'ercira, and $\Lambda$. G. Smith (1988): "Research Programme in $\mathrm{Na}$ tural I anguage l'rocessing - $\Lambda$ nnual Report", Nattie Project Documenl NA-16, Cambridge: SR I International.

Barnctl, B., H. I chmann, M. Zocpprity (1986): " $\Lambda$ word database for natural language processing", Proceeding.s //th International Conference on Computational linguistics COLING86 August 25th to 29th, 1986, Bomn, licderal Republic: of (icomany. 435-440.

lirk, Il. (1972): \%ur I.exik wisscnschaflicher fachlexte, München: llucber.

Ilcrog, O. et al. (1986): "IJIOC; -- linguistic and I ogic Methods for the Computational Understanding of Cicrman", I.IJOG-Report Ib, Stuttgart: IBM Deutschland.

Kuccra, II., W. N. Irancis (1967): Computational Analysis of Present-Day American English. Providence, RI: Brown University Press.

Oehler, II. (1980): KLETT (irund- und dufbauwortschatz Deutsch. Stuttgart: Klett.

Pregel, D., G. Rickheit (1987): Der Wortschaiz im Grundschulaller. Iliddeshcim: () Ims.

Wothke, K., U. Bandara, J. Kempf, IE. Keppel, K. Mohr, (j. Walch (1989): "The SPRING Speech Recognition System for German", in: Proceedings of Eurospeech '89. Vol. 2, 9-12. 